
\title{
3 Research Square \\ iTRAQ-based Comparative Proteomic Analysis Provides Insights Into Tobacco Callus Response to Carbon Nanoparticles
}

\section{Zhao Zhenjie}

China Tobacco Zhejiang Industrial Co Ltd https://orcid.org/0000-0002-6348-5469

Liwei Hu

ZTRI: Zhengzhou Tobacco Research Institute

Qiansi Chen

ZTRI: Zhengzhou Tobacco Research Institute

Huaxin Dai

ZTRI: Zhengzhou Tobacco Research Institute

Xiangyu Meng

China Tobacco Henan Industrisl Co Ltd

Qisheng Yin

ZTRI: Zhengzhou Tobacco Research Institute

Taibo Liang ( $\nabla$ taibol@163.com )

Zhengzhou Tobacco Research Institute of CNTC, Zhengzhou, China; https://orcid.org/0000-0001-86594644

Research

Keywords: Carbon nanoparticles, tobacco callus, iTRAQ, proteomics

Posted Date: November 19th, 2020

DOI: https://doi.org/10.21203/rs.3.rs-109134/v1

License: (a) (1) This work is licensed under a Creative Commons Attribution 4.0 International License.

Read Full License 


\section{Abstract}

Background. Carbon nanomaterials (CNMs) have attracted a great deal of research interest for their potential application in plants. Some types of CNMs have exhibited the ability on regulating the growth of plants, which showed a promising future in agriculture. However, detailed mechanism of their application in plants is still not well characterized especially at the molecular level.

\section{Methods.}

The biomass variation of tobacco callus was investigated to exposure of carbon nanoparticles (CNPs). During the incubation period, proteomic profiling in tobacco callus was investigated by using the isobaric tags for relative and absolute quantitation labeling (iTRAQ) coupled with 2D-LC MS/MS. The function of differentially expressed proteins were achieved by using a gene ontology (GO) and Kyoto encyclopedia of genes and genomes (KEGG) analysis by InterproScan, and qRT-PCR was used to confirm the results of the proteomic data.

Results. The results showed that the growth of tobacco callus was enhanced by CNPs, with the optimal concentration at $50 \mathrm{mg} / \mathrm{L}$. The expression levels of 198 cellular proteins were significantly up- or downregulated after CNPs treatment. These differentially expressed proteins were involved in mitochondria and calcium-mediated signaling.

Conclusions. We demonstrated CNPs have the ability to enhance the growth of tobacco callus. The proteomic profile changes of tobacco callus provided a deeper understanding of the highly complex regulatory mechanisms in tobacco callus exposed to CNPs.

\section{Background}

Nanotechnology is the technology for studying the properties and applications of materials in the nanoscale (mainly 1-100 nm) range. Since the discovery of fullerene, carbon nanomaterials (CNMs) including carbon nanotubes (CNTs), graphenes and other CNMs with different structural features have been discovered and applied. With the development of nanotechnology, the application of some CNMs attracted the attention of plant biologists, especially for some beneficial regulation on plant growth [1-3]. Some CNMs have been applied to agricultural purpose and demonstrated their potential to promote agricultural production [4-7]. Among carbon-based nanomaterials, such as single-walled carbon nanotubes (SWCNTs), multi-walled carbon nanotubes (MWCNTs), single-walled carbon nanohorns (SWCNHs), water-soluble carbon nano-onions and carbon nano-dots, have been investigated for their effects on plant growth. Although some researches has shown the adverse reaction on plants from exposure to a range of CNMs, the effects exerted by the CNMs always involve a high exposure concentration specific to plant species and growth environment [4]. Plenty of studies reported the positive effects of low-dose CNMs on plant growth and development [8]. The positive morphological effects include the promotion of the seed germination process, root elongation, drought stress, and the 
accumulation of biomass and so on [9-12]. However, the mechanism behind this is still not clarified well. More studies would be necessary to reveal the mechanism of CNMs on plants.

To explore the effects of CNMs on plant growth and development, a lot of researches has been conducted. Among them, the reports of carbon nanotubes appeared relatively early, and reports on the regulation of plant growth were relatively abundant. Khodakovskaya et al. [13] found that SWCNTs can significantly promote the growth of tobacco callus, the highest increase of fresh weight reached $64 \%$. Three genes were up-regulated in cells after callus was exposed to MWCNTs. These genes are involved in water transport, cell wall extension and cell division respectively. In the rhizobium-plant interaction, MWCNTs could improve the activity of nitrogenase and increase the level of the key gene (NIN) which regulates the development of nodules [14]. In some commercial crop, oxidized MWCNTs could penetrate the cell wall and enter the cytoplasm in roots, which promote cell elongation and dehydrogenase activity in the root system [15]. At low concentrations, MWCNTs show a strong positive effect on the growth of maize seedlings by enhancing water absorption and nutrient transport [8]. There are also reports about the changes of plant hormones in rice seedlings under carbon nanotube treatment, which indicated some possible relationships with reactive oxygen species [16]. Some raw CNPs isolated from biochar also can enhance the growth rate of wheat plants, and the optimum growth occurs at concentration of $50 \mathrm{mg} / \mathrm{L}$ in seeds [10].

The current studies mainly focused on the physiological changes in plants, activity of enzymes and some gene expression levels in plants. However, they are far from being able to reveal the detailed physiological and molecular mechanism of plants in response to CNMs. Proteomics is a useful tool for investigating some unknown changes in proteomes and achieves an evaluation of proteins on a global scale [17]. Given the crucial role of proteins in almost all cellular functions, it is necessary to study plants exposed to CNMs at the proteomic level. Proteomic profile analysis of mammalian cells exposed in SWCNTs was previously reported [18]. By studying changes in plants at the level of protein combinations, it will help to reveal the mechanism of action of CNMs on plants.

CNPs is a promising carbonaceous nanosized material. Electrolytic graphite method is an efficient way to prepare CNPs[19]. The CNPs prepared by this method can promote plant growth and improve plant nutrient utilization efficiency. There have been reports on improving the utilization rate of nutrient and improving root vitality and crop quality[20]. The aim of this study is to assess the promoting effect of CNPs on tobacco callus and using iTRAQ coupled with 2D-LC MS/MS to identify the proteins differentially expressed after exposed to CNPs.

\section{Methods}

\section{Synthesis and Characterization of CNPs}

CNPs were prepared as described in Chen et al[21] The morphology of CNPs were observed by a JEOL 2011 transmission electron microscope(TEM) at an accelerating voltage of $200 \mathrm{kV}$. Fourier Transform 
infrared (FTIR) spectroscopy of the CNPs were recorded by Thermo (USA) FTIR spectrophotometer.

\section{The culture of plant materials and experimental design}

Tobacco callus (Nicotiana tabacum L. Bright Yellow-2 cell) and tissue culture bottles were used as the material to carry the experiment, and tobacco callus was cultured in Murashige and Skoog (MS) medium agar plates [22]. The method used for tobacco callus culture was the same as described by Khodakovskaya et al [13]. The control medium was MS medium containing phytagel $(2.5 \mathrm{~g} / \mathrm{L})$ and 2, 4Dichlorophenoxyacetic acid $(1 \mathrm{mg} / \mathrm{L})$. The CNPs medium was made up of control medium added CNPs at the concentrations of $0,12.5,25,50$ and $100 \mathrm{mg} / \mathrm{L}$. Three equal amounts ( $300 \mathrm{mg}$ ) of initial calluses (inoculum), were placed in each tissue culture bottle and the calluses were cultured in the dark condition at $26-28{ }^{\circ} \mathrm{C}$ for 25 days. The samples were collected and weighed, then dried in an oven at $55^{\circ} \mathrm{C}$ until constant dry weight.

\section{Transmission Electron Microscopy (TEM) analysis of tobacco cell and CNPs}

After 25 days incubation, tobacco callus exposed to CNPs and control were dissected, and the upper cells in callus, which is away from the surface of phytagel, were carefully collected. The samples were fixed in phosphate buffered $2 \%$ glutaraldehyde, postfixed with $1 \%$ osmium tetroxide for 2 hours. Then, the samples were dehydrated in a graded series of ethanol $(30 \%, 50 \%, 70 \%$ and $90 \%)$ and acetone $(90 \%$ and three times with 100\%), and embedded in Epon resin. Then, the samples were sectioned with a Leica ultrathin microtome (50-70 nm thickness). Finally, it was stained with a Leica EM AC20 automatic stainer and dyed with uranyl acetate-lead citrate for about 1 hour. TEM samples were imaged by Hitachi HT7700. CNPs was observed by TEM on a copper grid after dilution. Image $\mathrm{J}$ software was used to calculate the diameter of CNPs.

\section{Protein extraction and digestion}

Tobacco callus were collected on the 8th day after treatment of CNPs. The samples were immediately frozen in liquid nitrogen and stored at $-80^{\circ} \mathrm{C}$. Samples were extracted with SDT (4\% (w/v) SDS, $100 \mathrm{mM}$ Tris/HCl pH 7.6, 0.1M DTT) lysis method, and protein quantification was performed using the BCA method. Trypsin digestion with FASP( Filter aided proteome preparation) method was performed on each sample, then the $\mathrm{C}_{18}$ Cartridge was used to desalt the enzymatic peptide fragment [23]. The peptide was lyophilized and then a $40 \mu \mathrm{L}$ dissolution buffer was used to reconstitute the peptide $\left(\mathrm{OD}_{280}\right)$.

\section{iTRAQ labelling and LC-MS/MS analysis}

Each sample was taken $100 \mu \mathrm{g}$ peptide, labelled with iTRAQ Reagent-8 plex Multiplex Kit (AB Sciex U.K.) according to the manufacturer's instructions. Each tagged set of peptides was pooled and fractionated using AKTA Purifier 100. The absorbance at $214 \mathrm{~nm}$ was monitored during the elution and the eluted fractions were collected every $1 \mathrm{~min}$ and lyophilized using a $\mathrm{C}_{18}$ Cartridge desalting. Each graded sample was separated using the Easy nLC HPLC system in nanoliter flow. Samples were chromatographed and 
analyzed by Q-Exactive mass spectrometry. The precursor ion scan range is $300-1800 \mathrm{~m} / \mathrm{z}$. The first MS resolution is 70000 at $200 \mathrm{~m} / \mathrm{z}$, and the second MS resolution is 17500 at $200 \mathrm{~m} / \mathrm{z}$.

\section{Database search and protein quantification}

Mass spectrometry raw data was screened and quantified using software Mascot2.2 and Proteome Discover1.4. The data was searched against the Uniprot Nicotiana tabacum database (released in July 2017). Search parameters were set as follows: Trypsin was used to conduct the search which allowed for two missed cleavages per peptide. Peptide and fragment tolerance were $\pm 20 \mathrm{ppm}$ and $0.1 \mathrm{Da}$ respectively. Only unique peptides which was reported with a cumulative confidence $>95 \%$ were identified. The quantification of protein was that the protein ratios were calculated as the median of only unique peptides of the protein. Then, all peptide ratios were normalized by the median protein ratio. The median protein ratio should be 1 after the normalization.

\section{Bioinformatics functional analysis}

The Function of the differentially expressed protein was annotated based on sequence similarities to sequences in the public Uniport database [24]. A standard T-test was used for the statistics analysis by the software $\mathrm{R}$ to determine the significance of changes in each protein between biological conditions [25]. Functional classification of the differentially expressed proteins was conducted based on gene ontology (GO) analysis [26].

\section{RNA extraction and qRT-PCR analysis}

Total RNA was extracted from the tobacco callus by using RNA iso plant Plus reagent (TaKaRa Bio, Otsu, Japan) and then cDNA was synthesized in a $20 \mu \mathrm{L}$ reaction solution by using a Transcriptor First-Strand cDNA Synthesis Kit (Roche), following the manufacturer's instructions. All qRT-PCR amplification reactions were performed by using a LightCycler 96 Real-Time PCR System (Roche). PCR reactions were run in triplicate. The actin (AB158612) was used as internal reference to normalize the expression data [13]. Relative quantification of the transcription level was determined by using the 2- $\Delta \Delta C T$ method [27]. The specific primers and the annealing temperatures are presented in Table 1.

Table 1

Design of primers used for qRT-PCR analysis.

\begin{tabular}{|llll|}
\hline Uniprot ID & Genesymbol & Forward primer $\left(\mathbf{5}^{\prime} \rightarrow \mathbf{3}^{\prime}\right)$ & Reverse primer $\left(\mathbf{5}^{\prime} \rightarrow \mathbf{3}^{\prime}\right)$ \\
\hline A0A1S3ZIV3 & Tim9 & GCCATGATTGACCAGCTCCA & CCTGACACAGGTCTCCTCCT \\
\hline A0A1S4BAA7 & Cox6b & GCACTGTTTCACACGCTACG & GGAAAGTCCCGTTCTCCCTC \\
\hline A0A1S3YMB4 & Cytc & TGAACAAGCTCCAGCAGGTGA & CTTGTTTGTGACCAGCACCTT \\
\hline A0A1S3ZUS5 & Cb/3 & GTTGCAGTGCCTAGACGGTA & AGAGCTTCAATCTCACTGACAC \\
\hline Q76ME6 & Ntcam10 & GACGGCGATGGTTGCATTAC & GCTCCTCCTCCGAGTCTGTA \\
\hline A0A1S4DQT4 & Cbs & ATGAAGAGACGCGGAGTGAC & TGAGGAAGATTGTCCCGGTC \\
\hline
\end{tabular}




\section{Results}

\section{Characterization}

The morphology and size distribution of CNPs were characterized by TEM. CNPs are quasi spherical (Fig. 1B). Diameter distribution of CNPs show that the size ranges from 28 to $77 \mathrm{~nm}$, agrees well with the Gaussian distribution (Fig. 1C). FTIR also was used to identify the functional groups of CNPs (Fig. 1D). A broad peak centered at $3420 \mathrm{~cm}^{-1}$ associated with the stretching vibrations of $\mathrm{O}-\mathrm{H}$. The existence of a sharp absorption peak at $1100,1640 \mathrm{~cm}^{-1}$ associated with $\mathrm{C}-\mathrm{O}, \mathrm{C}=0$ stretching is observed, revealing the presence of $\mathrm{COOH}$.

\section{CNPs induce growth enhancement of tobacco callus and TEM analysis}

After 25 days of cell incubation treated by CNPs, the effects on the promotion of tobacco callus growth were clearly observed (Fig. 2). $50 \mathrm{mg} / \mathrm{L}$ and $100 \mathrm{mg} / \mathrm{L}$ CNPs enhanced cell growth with fresh weight by $30.1 \%$ and $18.4 \%$, and the dry weight increased by $33.9 \%$ and $17.8 \%$, respectively (Fig. $2 \mathrm{~A}$ ). At the concentration of $50 \mathrm{mg} / \mathrm{L}$, it indicated a significant increase of growth in tobacco callus (Fig. 2B). CNPs in cell were observed by TEM, and CNPs were located around the cell wall (Fig. 2C).

\section{Identification of differentially expressed proteins in tobacco callus in response to CNPs treatment}

iTRAQ-based comparative proteomic analysis was used to enable comparison of the proteomic of tobacco callus in response to CNPs treatment. Proteins were extracted from the above-mentioned tobacco callus of $50 \mathrm{mg} / \mathrm{L}$ CNPs treatment (CNPs-50) and untreated control. Proteins were identified and quantified by iTRAQ labelling and LC-MS/MS analysis, respectively. A total of 6711 proteins were detected in these samples (\$1 Table). Among these proteins, 198 displayed significant differences in expression levels, accounting for 2.95\% of the total number of proteins (S2 Table). In between, 89 proteins exhibited increased and 109 decreased (CNPs-50: Control ratio $<0.71$ or ratio $>1.4$, q-value $<$ 0.05), respectively (Fig. 3A). The fold variation was calculated as the average value obtained from three replicates. Hierarchical clustering of all differentially regulated proteins indicated that CNPs induced great changes in protein levels (Fig. 3B).

\section{GO and pathway enrichment analysis of differentially expressed proteins}

In order to evaluate the biological significance of 198 differential proteins and their functional enrichment, the function of differentially expressed proteins were achieved by using a gene ontology (GO) and KEGG analysis by InterproScan. Results showed that the differentially expressed proteins were mainly involved in "ubiquinol-cytochrome-c reductase activity", "protein domain specific binding", "planttype secondary cell wall biogenesis", "cytochrome-c oxidase activity", and "calcium-dependent 
phospholipid binding" in GO enrichment (Fig. 4A). Interestingly, plenty of GO items were related to mitochondrion. Furthermore, after treatment with CNPs, many proteins located in mitochondrion were viewed at a higher level. This was especially true for mitochondrial import inner membrane translocase and cytochrome $\mathrm{c}$.

Complex biological functions of protein were also classified by KEGG pathway analysis to get valuable information. The enrichment item of KEGG showed that differentially expressed proteins were mainly involved in oxidative phosphorylation, calcium signaling pathway and carbon metabolism (Fig. 4B). Checking the detail of proteins, such as calmodulin, may play an important role in plants under treatment of CNPs.

\section{Validation of the gene expression level of the differentially expressed proteins by qRT-PCR}

It was confirmed that the significant changes in specific proteins also occurred the level of gene expression in response to CNPs. Six proteins whose expression changed significantly, and with different biological functions and cellular locations, were selected to evaluate the gene changes by qRT-PCR. The gene Tim9, Cox6b, Cb/3, Ntcam10, Cytc and Cbs of selected proteins showed the same trend with the proteomic changes (Fig. 5).

\section{Discussion}

The phenomenon of CNPs promoting the growth of tobacco callus was similar to that of MWCNTs [13] and SWCNHs [28]. The stimulating effect of CNPs has been reported previously. In this study, CNPs significantly promoted the growth of tobacco callus. Meanwhile, CNPs has a concentration effect, suitable concentration is beneficial to the growth of tobacco callus. Lahiani et al [29] demonstrated that CNMs with different morphologies can promote cell growth, seed germination, and plant growth. Hence, the positive effect may share similar mechanisms in plants. Previous research suggested that CNPs was biocompatible with BY-2 cells [21]. The phenomenon that some CNMs are absorbed by plants and then transported to the cell gap or into the cell interior has been observed in many electron microscope experiments $[15,30]$. In this study, CNPs particles were observed to adhere to the cell wall. This is different from previous report that CNPs was found inside of tobacco cell in suspension cell culture [21]. The reason could be the different culture conditions on the growth of tobacco cells and the length of cultivation period.

In this study, we performed a general assessment of differential proteins by using the iTRAQ technology. 198 proteins were up- or down-regulated by the exposure with CNPs, indicating that CNPs strongly influenced the physiological process of tobacco callus. The items of KEGG and GO enrichment were associated with mitochondria and calcium-mediated signaling. Mitochondria are important organelles inside plant cells. Among the top 20 up- and 20 down-regulated proteins, our study found that a large portion of these proteins were mitochondria-related such as membrane transferase and cytochrome $c$ oxidase. Therefore, it is likely that CNPs strongly affects the function of mitochondria. It was previously 
reported that some of the SWCNTs crossed the membrane and were located inside the mitochondria, stimulating cell growth in Arabidopsis mesophyll cells only at a low dose $(15 \mu \mathrm{g} / \mathrm{mL})$ [31]. In this study, we identified several members in TIM protein family including TIM9, TIM10 and TIM13, which increased dramatically after treatment. TIM complex is a part of the chain for transferring proteins from cytoplasm to mitochondrial matrix [32]. The gene Tim9 showed the same trend with the proteomic changes. TIM9 play critically important roles during sporophyte initiation, which performs non-redundant regulation of early embryonic cells and endosperm free nuclear division and development[33]. Previously report also showed that mitochondrial protein TIM50 affects hypocotyl cell elongation through intracellular ATP level in Arabidopsis[34] and TIM21 affects seedling development in Arabidopsis [35]. This may be associated with increased protein transport to the mitochondrial matrix.

Intracellular energy is crucial for the growth of plant cell. This level of energy is expected to have an important effect on cell proliferation and cell elongation. Among the top 20 up-regulated proteins, cytochrome $\mathrm{c}$ oxidase and cytochrome $\mathrm{c}$ are two other increased expressed proteins. They are located in the inner mitochondrial membrane and are involved in the electron transport chain. This may suggest that the energy processing activities of tobacco callus increased and meet the enhanced energy requirement after treated by CNPs. The analysis of GO function enrichment also revealed plenty of items in the mitochondria. Therefore, we presumed that effect of CNPs treatment on mitochondrial function of callus is closely related to its growth.

The analysis of proteomics data showed that some differentially expressed proteins were annotated as calmodulin (CaM), and the expression level was significantly up-regulated (up-regulated by 1.5 times). The calcium signaling pathway, was significantly enriched among the differently expressed proteins. Calmodulin is a calcium-binding protein that is only activated after binding to $\mathrm{Ca}^{2+}$, and hormones can regulate calmodulin activity by affecting intracellular $\mathrm{Ca}^{2+}$ concentration changes. It has been reported that the $\mathrm{Ca}^{2+}-\mathrm{CaM}$ signaling system mediates auxin-mediated plant cell signaling and regulates the growth of corn sheaths [36]. Some research shows transcript level of auxin efflux carrier increased induced by graphene oxide [37]. However, we did not detect the changes in some hormone-related proteins, this may be due to different cell culture periods and type of carbon nanomaterials. So, further research is needed. In addition, CaM-like protein (CML) also showed 1.5-fold up-regulation. It has been reported that $\mathrm{CML}$ regulates plant cell morphology and division [38]. Exploring the changes of calmodulin in callus treated by CNPs provides a new idea for studying the mechanism of this promoting effect.

\section{Conclusions}

CNPs have the ability to enhance the growth of tobacco callus. The proteomic profile changes of tobacco callus after CNPs treatment were compared using iTRAQ-based quantitative proteomics technology, and 198 proteins with significant changes regulated by adding CNPs-50 in expression levels were identified. The differentially expressed proteins are involved in mitochondrial function and calcium signaling fluxes of callus, which provides new insights into the molecular mechanisms of CNPs. These data can help us to understand the effect mechanisms of CNPs on plant growth at the protein level. 


\section{List Of Abbreviations}

CNMs Carbon nanomaterials

CNPs Carbon nanoparticles

GO Gene ontology

iTRAQ Isobaric tag for relative and absolute quantitation

KEGG Kyoto encyclopedia of genes and genomes

TBY-2 cell Nicotiana tabacum L. Bright Yellow-2 cell

TEM Transmission Electron Microscopy

\section{Declarations}

\section{Acknowledgements}

Not applicable.

\section{Authors' contributions}

QY and TL conceived and designed the experiments. ZZ QC, and XM performed the experiments. ZZ, LH, and HD participated in the data analysis. $Z Z$ and TL drafted the manuscript. TL provided guidance for preparing the manuscript. All authors read and approved the final manuscript.

\section{Funding}

The work described in this paper was substantially supported by Zhengzhou Tobacco Research Institute Dean Fund (112017CA0090), Sichuan Tobacco Company Project(LSYC201601), and Science and technology project of China Tobacco Corporation (110201902004).

\section{Availability of data and materials}

All data generated and analyzed during this study are included in this published article.

\section{Ethics approval and consent to participate}

Not applicable. 


\section{Consent for publication}

Not applicable.

\section{Competing interests}

The authors declare that they have no competing interests.

\section{References}

1. Cañas JE, Long M, Nations S, Vadan R, Dai L, Luo M, et al. Effects of functionalized and nonfunctionalized single-walled carbon nanotubes on root elongation of select crop species. Environmental Toxicology \& Chemistry. 2008;27(9):1922-1931.

2. Lahiani MH, Dervishi E, Chen J, Nima Z, Gaume A, Biris AS, et al. Impact of Carbon Nanotube Exposure to Seeds of Valuable Crops. Acs Applied Materials \& Interfaces. 2013;5(16):7965-7973.

3. Verma SK, Das AK, Gantait S, Kumar V, Gurel E. Applications of carbon nanomaterials in the plant system: A perspective view on the pros and cons. The Science of the total environment. 2019;667:485-499.

4. Mukherjee A, Majumdar S, Servin AD, Pagano L, Dhankher OP, White JC. Carbon Nanomaterials in Agriculture: A Critical Review. Front Plant Sci. 2016;7:172.

5. Zhang BT, Zheng X, Li HF, Lin JM. Application of carbon-based nanomaterials in sample preparation: A review. Analytica Chimica Acta. 2013;784(12):1-17.

6. Kole C, Kole P, Randunu KM, Choudhary P, Podila R, Pu CK, et al. Nanobiotechnology can boost crop production and quality: first evidence from increased plant biomass, fruit yield and phytomedicine content in bitter melon (Momordica charantia ). Bmc Biotechnology. 2013;13(1):37.

7. Lijuan Z, Li L, Aodi W, Huiling Z, Min H, Honghong W, et al. Nano-Biotechnology in Agriculture: Use of Nanomaterials to Promote Plant Growth and Stress Tolerance. Journal of agricultural and food chemistry. 2020;68(7):1935-1947.

8. Tiwari DK, Dasgupta-Schubert N, Villaseñor Cendejas LM, Villegas J, Carreto Montoya L, Borjas García SE. Interfacing carbon nanotubes (CNT) with plants: enhancement of growth, water and ionic nutrient uptake in maize (Zea mays) and implications for nanoagriculture. Applied Nanoscience. 2013;4(5):577-591.

9. Rico CM, Majumdar S, Duarte-Gardea M, Peralta-Videa JR, Gardea-Torresdey JL. Interaction of nanoparticles with edible plants and their possible implications in the food chain. J Agric Food Chem. 2011;59(8):3485-3498.

10. Saxena M, Maity S, Sarkar S. Carbon nanoparticles in 'biochar' boost wheat (Triticum aestivum) plant growth. RSC Adv. 2014;4(75): 39948-39954. 
11. Ali MH, Sobze JM, Pham TH, Nadeem M, Liu C, Galagedara L, et al. Carbon Nanoparticles Functionalized with Carboxylic Acid Improved the Germination and Seedling Vigor in Upland Boreal Forest Species. Nanomaterials (Basel, Switzerland). 2020;10:176.

12. Kim TY, Lee SH, Ku H, Lee SY. Enhancement of Drought Tolerance in Cucumber Plants by Natural Carbon Materials. Plants (Basel, Switzerland). 2019;8(11):446.

13. Khodakovskaya MV, Silva KD, Biris AS, Dervishi E, Villagarcia H. Carbon Nanotubes Induce Growth Enhancement of Tobacco Cells. Acs Nano. 2015;6(3):2128-2135.

14. Yuan Z, Zhang Z, Wang X, Li L, Cai K, Han H. Novel impacts of functionalized multi-walled carbon nanotubes in plants: promotion of nodulation and nitrogenase activity in the rhizobium-legume system. Nanoscale. 2017;9(28):9921-9937.

15. Wang X, Han H, Liu X, Gu X, Chen K, Lu D. Multi-walled carbon nanotubes can enhance root elongation of wheat ( Triticum aestivum ) plants. Journal of Nanoparticle Research. 2012;14(6):841851.

16. Zhang H, Yue M, Zheng X, Xie C, Zhou H, Li L. Physiological effects of single- and multi-walled carbon nanotubes on rice seedlings. IEEE transactions on nanobioscience. 2017;16:563-570.

17. Anderson NL, Anderson NG. Proteome and proteomics: new technologies, new concepts, and new words. Electrophoresis. 1998;19(11):1853-1861.

18. Yuan J, Gao H, Sui J, Duan H, Chen WN, Ching CB. Cytotoxicity Evaluation of Oxidized Single-Walled Carbon Nanotubes and Graphene Oxide on Human Hepatoma HepG2 cells: An iTRAQ-Coupled 2D LC-MS/MS Proteome Analysis. Toxicological Sciences An Official Journal of the Society of Toxicology. 2012;126(1):149-161.

19. Chen L, Yang J, Li X, Liang T, Nie C, Xie F, et al. Carbon nanoparticles enhance potassium uptake via upregulating potassium channel expression and imitating biological ion channels in BY-2 cells. Journal of Nanobiotechnology. 2020;18(1):21.

20. Jian Y, Taibo L, Haijiang L, Qisheng Y, Yanling Z, Hanping Z, et al. Effects of Nano-carbon Sol on Physiological Characteristics of Root System and Potassium Absorption of Flue-cured tobacco. Tobacco Science \& Technology. 2015;48(01):7-11.

21. Chen L, Wang H, Li X, Nie C, Liang T, Xie F, et al. Highly hydrophilic carbon nanoparticles: uptake mechanism by mammalian and plant cells. Rsc Advances. 2018;8(61):35246-35256.

22. Murashige T, Skoog F. A Revised Medium for Rapid Growth and Bio Assays with Tobacco Tissue Cultures. Physiologia Plantarum. 1962;15(3):473-497.

23. JR W, Zougman A, N N, M M. Universal sample preparation method for proteome analysis. Nature Methods. 2009;6(5):359-362.

24. Consortium UP. UniProt: a hub for protein information. Nucleic Acids Research. 2015;43:204-212.

25. Team CR. Team RDC.R: A Language And Environment For Statistical Computing. R Foundation for Statistical Computing: Vienna, Austria. Computing. 2013;14:12-21. 
26. Mitchell A, Chang H-Y, Daugherty L, Fraser M, Hunter S, Lopez R, et al. The InterPro protein families database: the classification resource after 15 years. Nucleic Acids Research. 2015;43:213-221.

27. Livak KJ, Schmittgen TD. Analysis of relative gene expression data using real-time quantitative PCR and the 2(-Delta Delta C(T)) Method. Methods. 2001;25(4):402-408.

28. Lahiani MH, Chen J, Irin F, Puretzky AA, Green MJ, Khodakovskaya MV. Interaction of carbon nanohorns with plants: Uptake and biological effects. Carbon. 2015;81:607-619.

29. Lahiani MH, Dervishi E, Ivanov I, Chen J, Khodakovskaya M. Comparative study of plant responses to carbon-based nanomaterials with different morphologies. Nanotechnology. 2016;27(26):265102.

30. Yan S, Zhao L, Li H, Zhang Q, Tan J, Huang M, et al. Single-walled carbon nanotubes selectively influence maize root tissue development accompanied by the change in the related gene expression. Journal of Hazardous Materials. 2013;s246-247:110-118.

31. Yuan H, Hu S, Huang P, Song H, Wang K, Jing R, et al. Single Walled Carbon Nanotubes Exhibit DualPhase Regulation to Exposed Arabidopsis Mesophyll Cells. Nanoscale Research Letters. 2011;6(1):44.

32. Schwarzländer M, Fuchs P. Plant mitochondrial membranes: adding structure and new functions to respiratory physiology. Current Opinion in Plant Biology. 2017;40:147-157.

33. Deng Y, Zou W, Li G, Zhao J. TRANSLOCASE OF THE INNER MEMBRANE9 and 10 are essential for maintaining mitochondrial function during early embryo cell and endosperm free nucleus divisions in Arabidopsis. Plant physiology. 2014;166,853-868.

34. Kumar S, Yoshizumi T, Hongo H, Yoneda A, Hara H, Hamasaki H, et al. Arabidopsis mitochondrial protein TIM50 affects hypocotyl cell elongation through intracellular ATP level. Plant Science. 2012;183:212-217.

35. Hamasaki H, Yoshizumi T, Takahashi N, Higuchi M, Kuromori T, Imura Y, et al. SD3, an Arabidopsis thaliana Homolog of TIM21, Affects Intracellular ATP Levels and Seedling Development. Molecular plant. 2012;5(2):461-471.

36. Yang T, Poovaiah BW. Molecular and Biochemical Evidence for the Involvement of Calcium/Calmodulin in Auxin Action. Journal of Biological Chemistry. 2000;275(5): 3137-3143.

37. Feihong L, Chao S, Xuehan L, Xinyi Y, Chao L, Yanying S, et al. The effect of graphene oxide on adventitious root formation and growth in apple. Plant Physiology \& Biochemistry. 2018;129:122129.

38. Pina C, Pinto F, Feijã ${ }^{3}$ JA, Becker JD. Gene family analysis of the Arabidopsis pollen transcriptome reveals biological implications for cell growth, division control, and gene expression regulation. Plant Physiology. 2005;138(2):744-756.

\section{Figures}


A

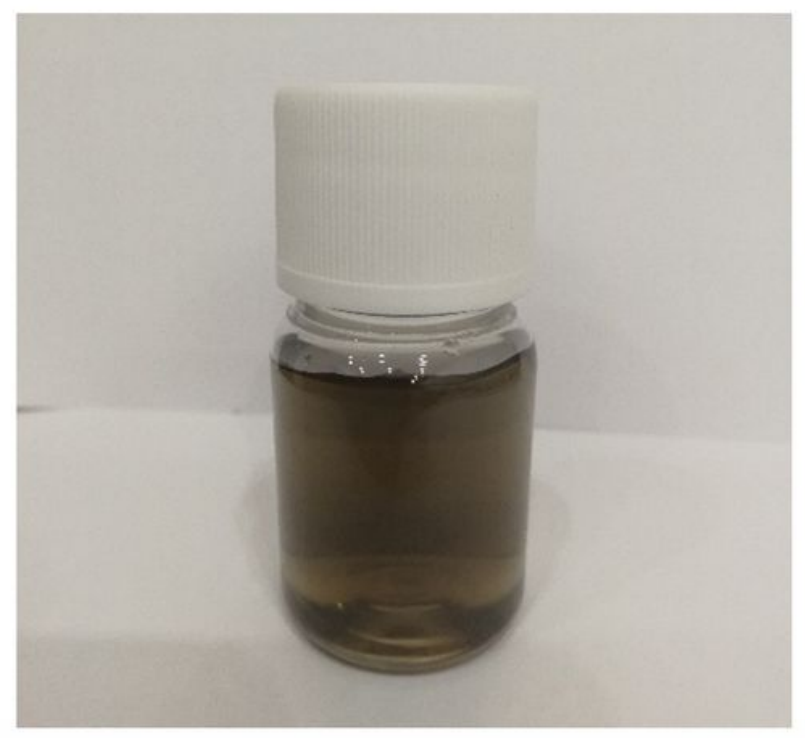

C

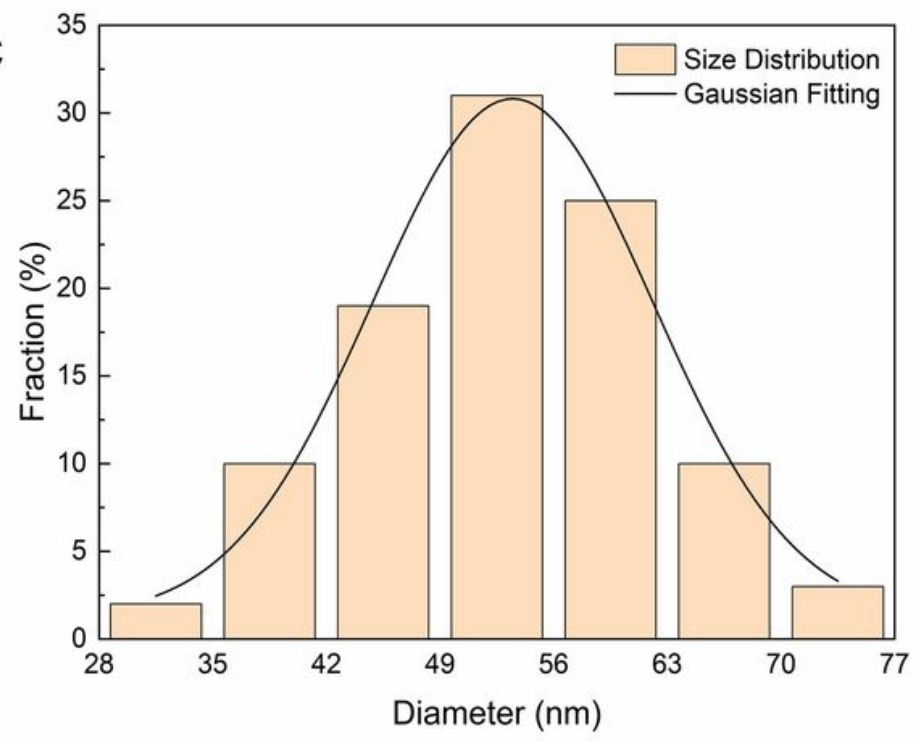

B

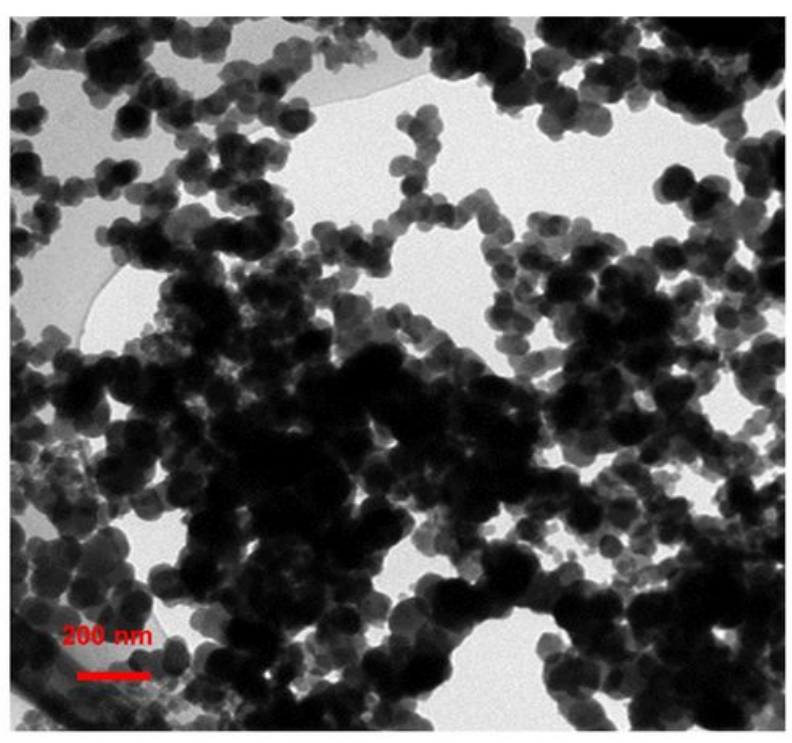

Binding Energy(eV)

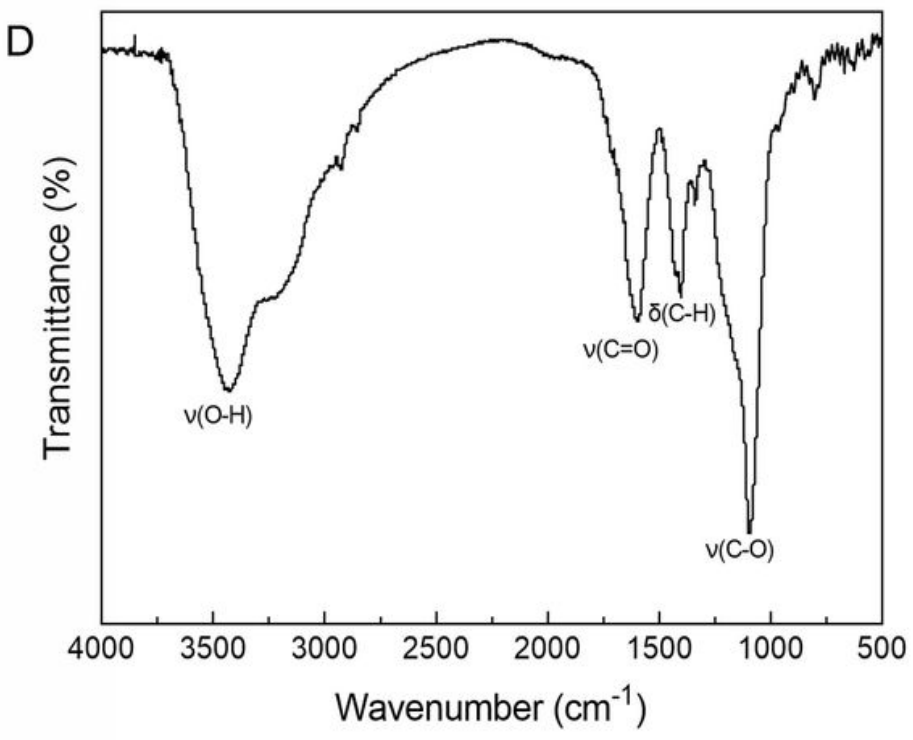

Figure 1

(A) CNPs is dispersed into water. (B) TEM images of the CNPs on Cu grid coated with ultrathin amorphous carbon film. (C) Statistical distribution of nano-carbon particle size, the black line is the Gaussian fitting curve. (D) FTIR spectra of CNPs. 
A

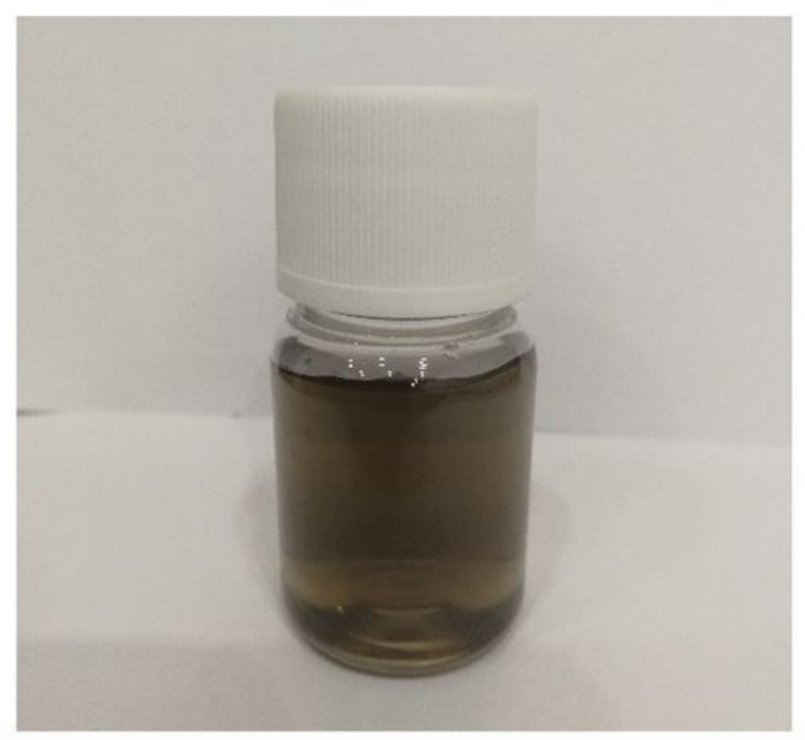

C

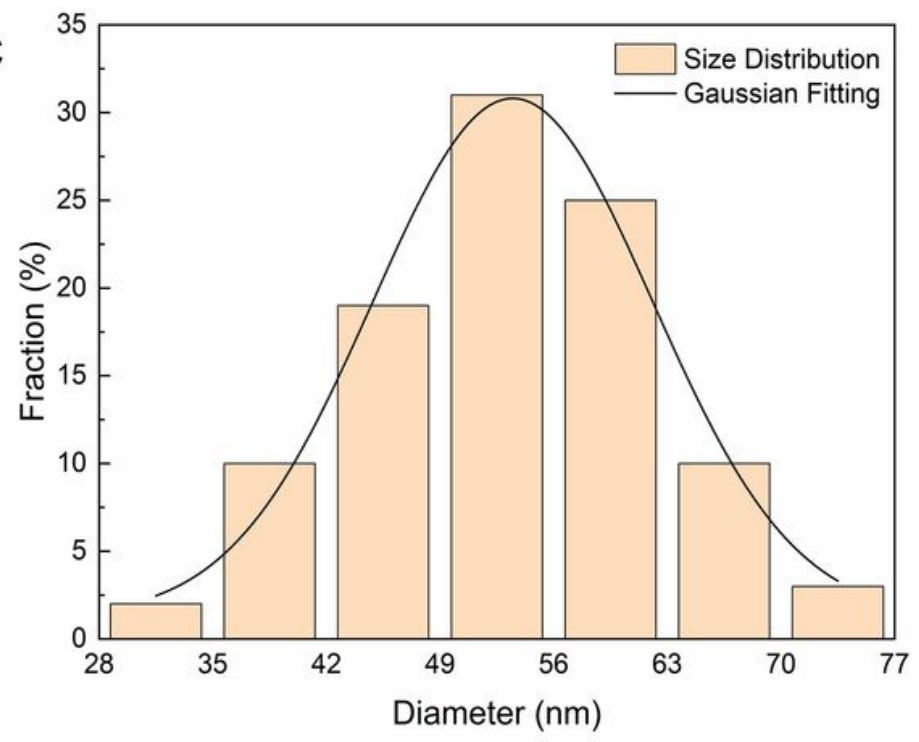

B

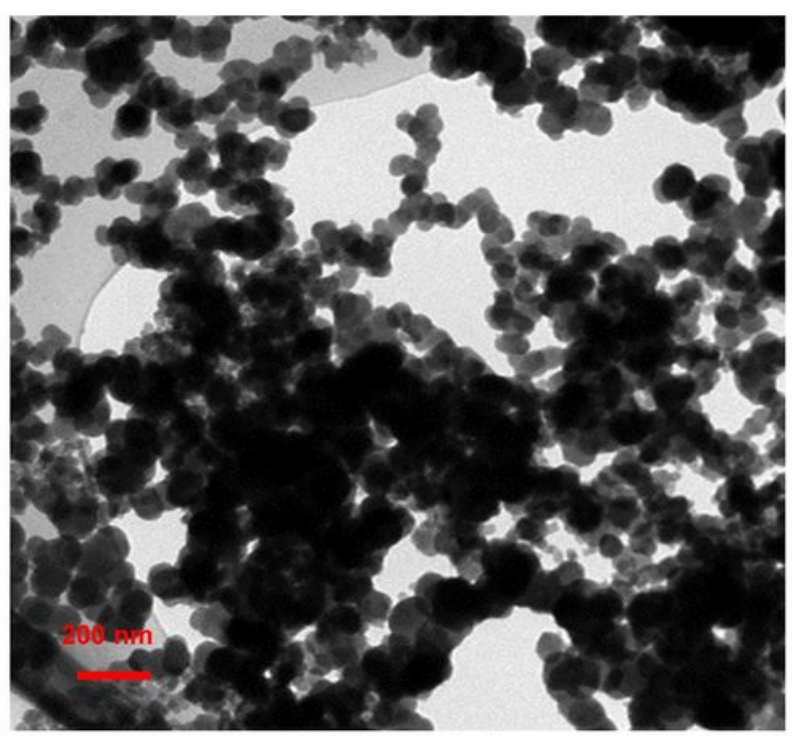

Binding Energy(eV)

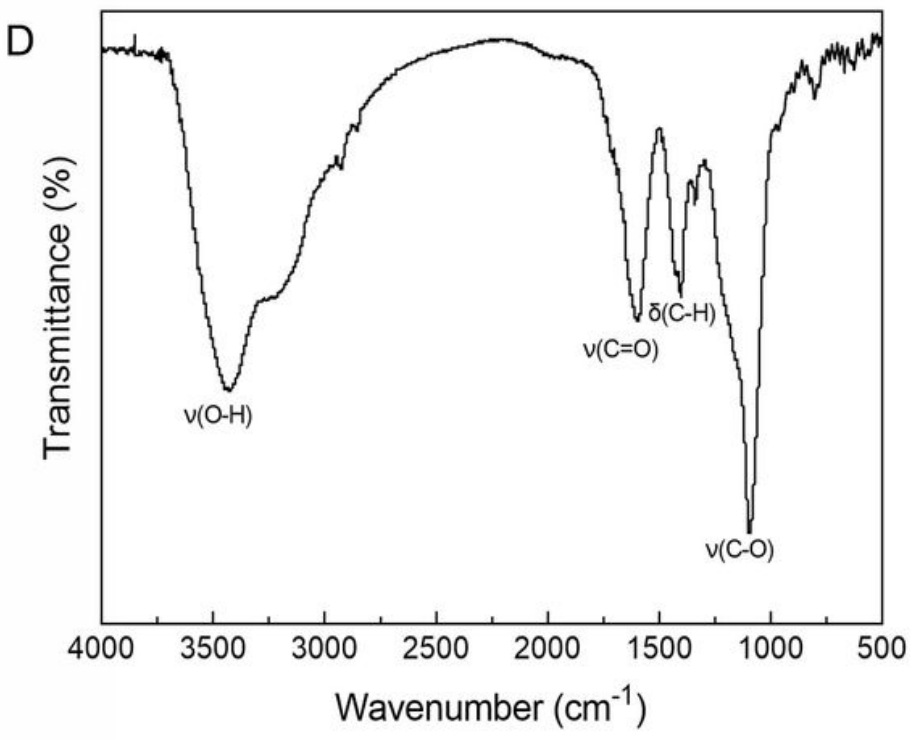

Figure 1

(A) CNPs is dispersed into water. (B) TEM images of the CNPs on Cu grid coated with ultrathin amorphous carbon film. (C) Statistical distribution of nano-carbon particle size, the black line is the Gaussian fitting curve. (D) FTIR spectra of CNPs. 

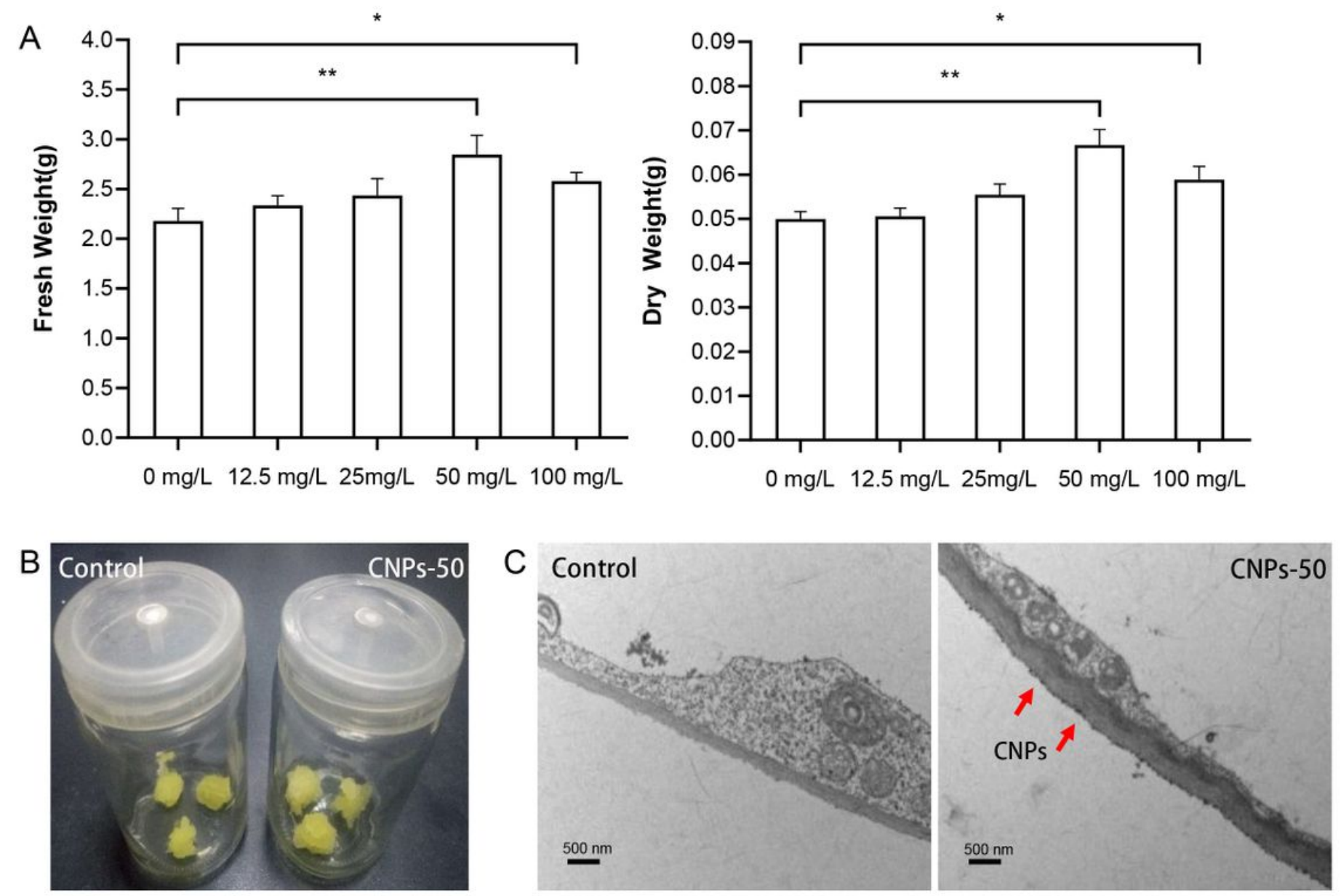

\section{Figure 2}

Effect of CNPs on the growth of tobacco callus. Biomass accumulation of tobacco callus cultured in MS medium and medium supplemented with CNPs. (A) Fresh weight and dry weight were determined (average $\pm S E, n=18$ ). Asterisks indicate significant differences between control and treatment determined by Student's t-test ( $*, P<0.05, * \star, P<0.01)$. (B) Optical image of the control (left) and the tobacco callus incubated with $50 \mathrm{mg} / \mathrm{L}$ CNPs for 25 days (right). (C) TEM images of untreated tobacco callus and treated with CNPs after 25 days at the concentrations of $50 \mathrm{mg} / \mathrm{L}$. 

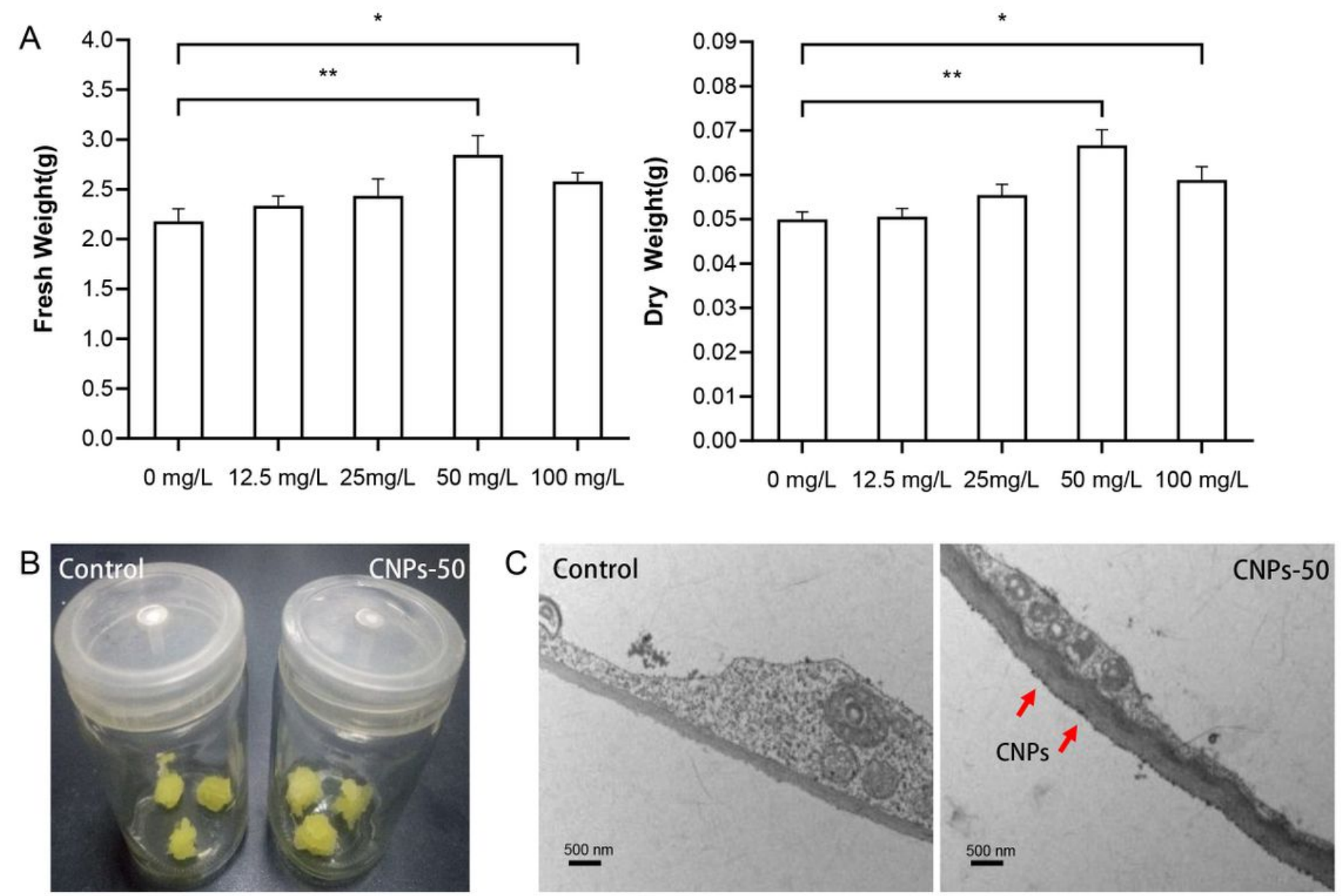

\section{Figure 2}

Effect of CNPs on the growth of tobacco callus. Biomass accumulation of tobacco callus cultured in MS medium and medium supplemented with CNPs. (A) Fresh weight and dry weight were determined (average $\pm S E, n=18$ ). Asterisks indicate significant differences between control and treatment determined by Student's t-test ( $*, P<0.05, * \star, P<0.01)$. (B) Optical image of the control (left) and the tobacco callus incubated with $50 \mathrm{mg} / \mathrm{L}$ CNPs for 25 days (right). (C) TEM images of untreated tobacco callus and treated with CNPs after 25 days at the concentrations of $50 \mathrm{mg} / \mathrm{L}$. 
A

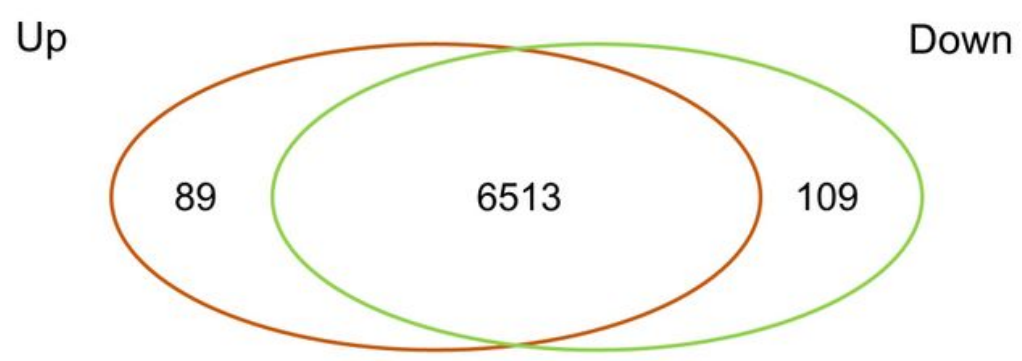

CNPs-50 vs. Control

B

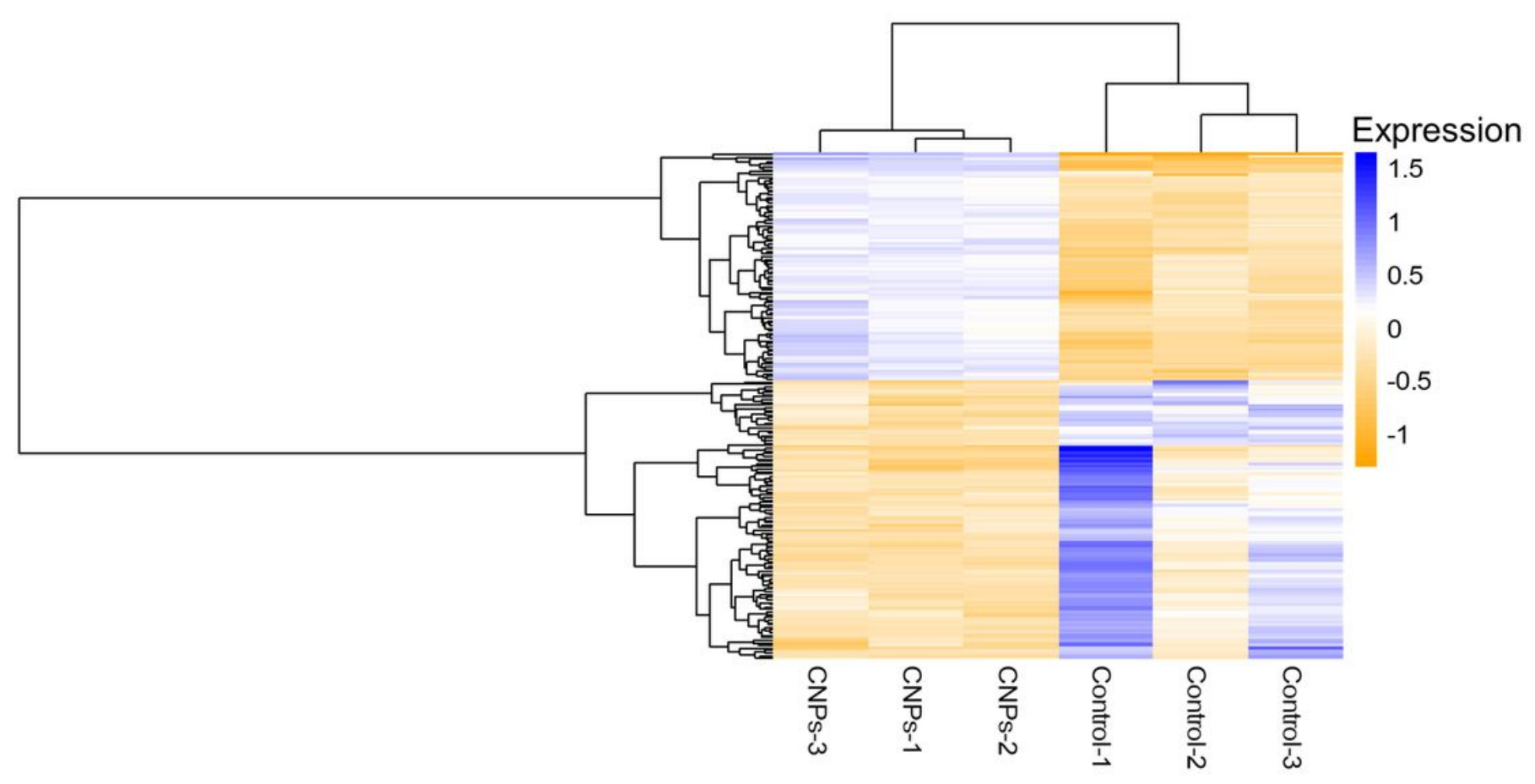

Figure 3

General overview of quantitative proteomic profiles. (A) Venn diagram of differentially expressed proteins for the CNPs-50 vs. Control comparison. (B) Hierarchical clustering of all the differentially expressed proteins Top, sample tree (CNPs-1, CNPs-2, CNPs-3, three replicates treated with $50 \mathrm{mg} / \mathrm{L}$ CNPs treatment; Control-1, Control-2, Control-3, three replicates of controls). The colour scale bar on the top, yellow and blue indicate decreased and increased levels respectively, and white indicates no significant changes in proteins. 
A

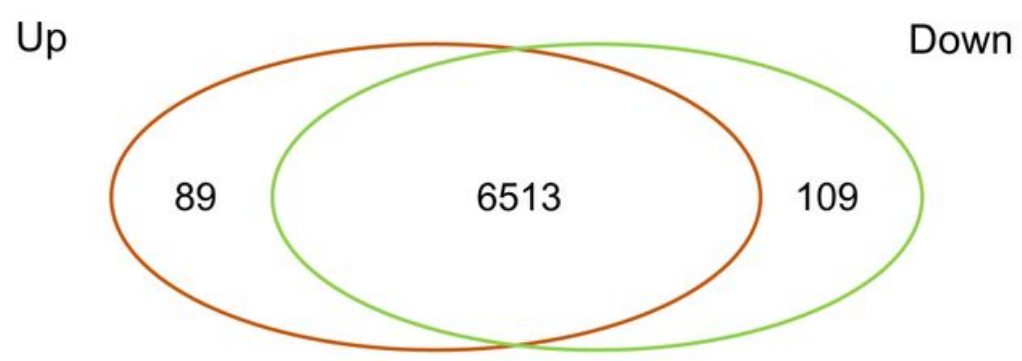

CNPs-50 vs. Control

B

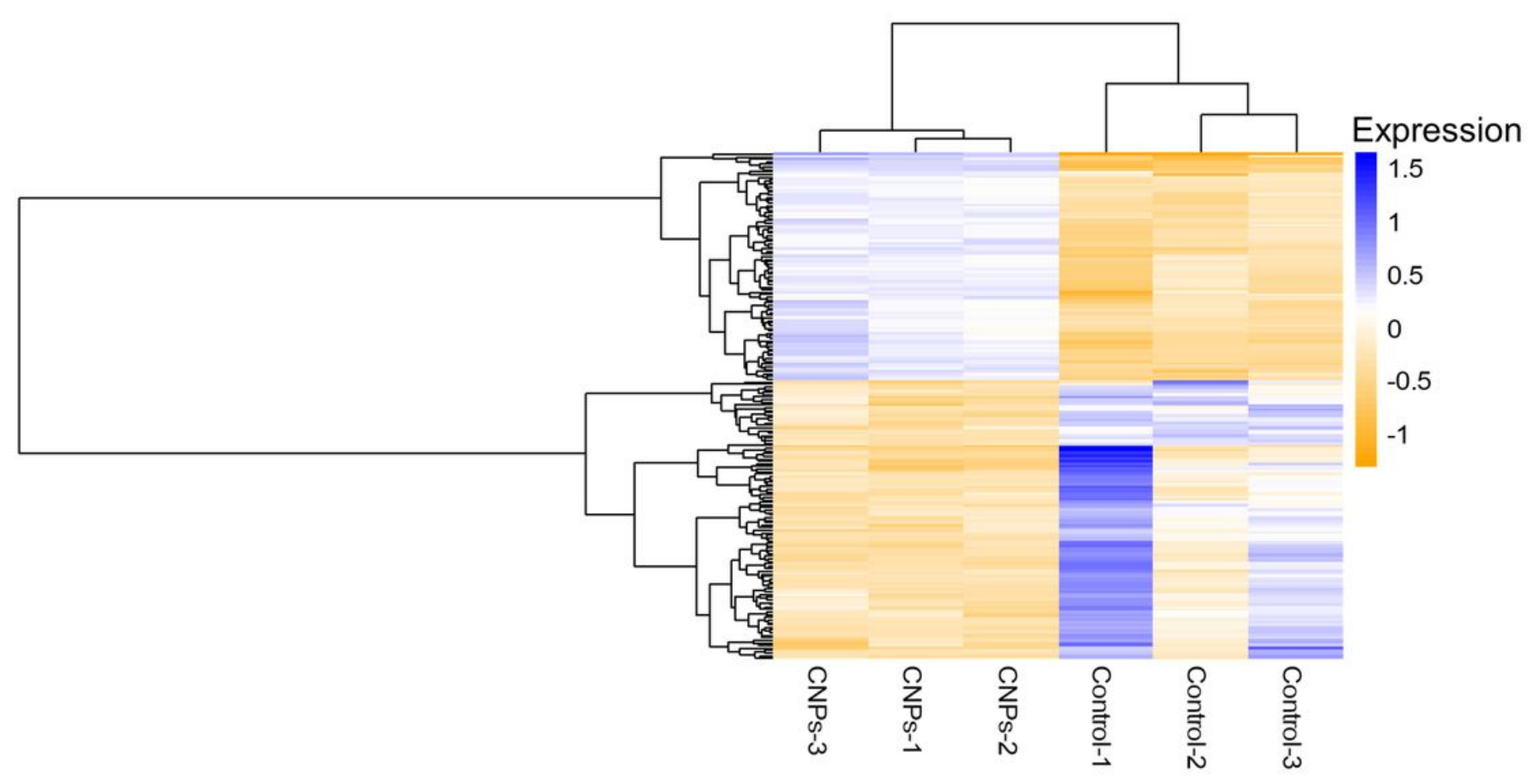

Figure 3

General overview of quantitative proteomic profiles. (A) Venn diagram of differentially expressed proteins for the CNPs-50 vs. Control comparison. (B) Hierarchical clustering of all the differentially expressed proteins Top, sample tree (CNPs-1, CNPs-2, CNPs-3, three replicates treated with $50 \mathrm{mg} / \mathrm{L}$ CNPs treatment; Control-1, Control-2, Control-3, three replicates of controls). The colour scale bar on the top, yellow and blue indicate decreased and increased levels respectively, and white indicates no significant changes in proteins. 


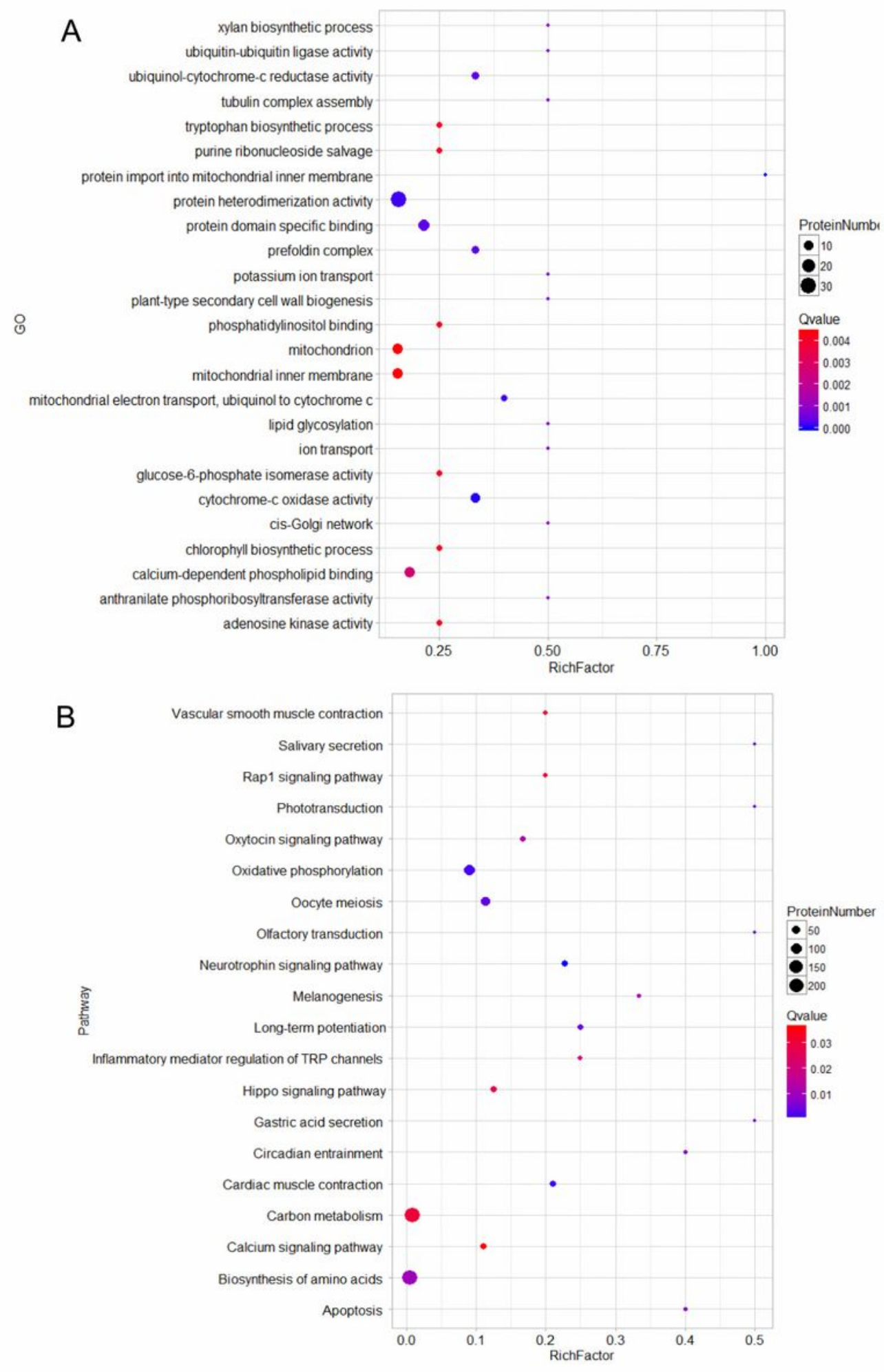

\section{Figure 4}

GO and KEGG-pathway enrichment analysis of the 198 differentially expressed proteins based on their functional annotations. (A) Top 25 enriched GO items for the differently expressed proteins; (B) Top 20 enriched pathways for the differently expressed proteins. 


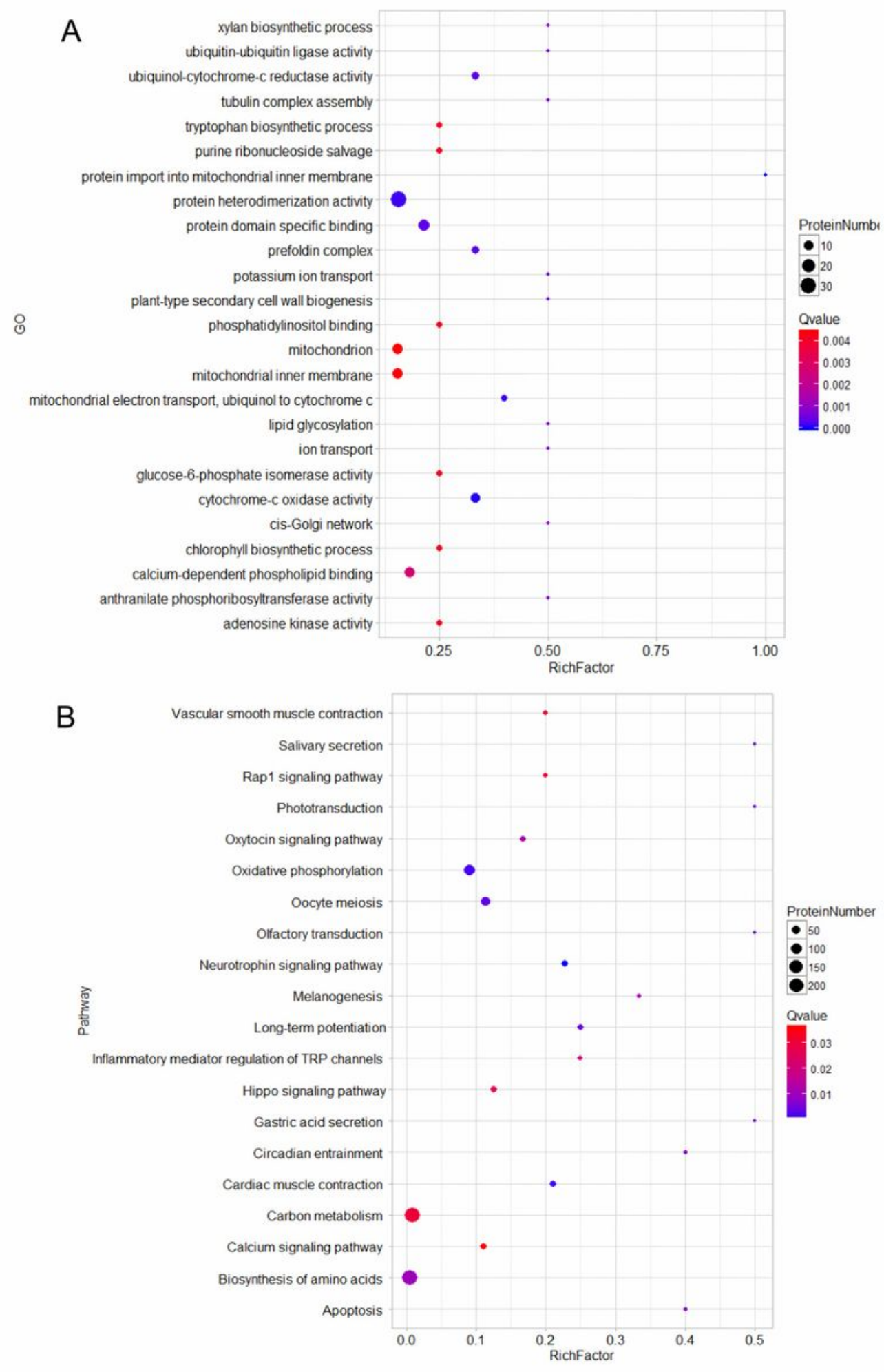

\section{Figure 4}

GO and KEGG-pathway enrichment analysis of the 198 differentially expressed proteins based on their functional annotations. (A) Top 25 enriched GO items for the differently expressed proteins; (B) Top 20 enriched pathways for the differently expressed proteins. 


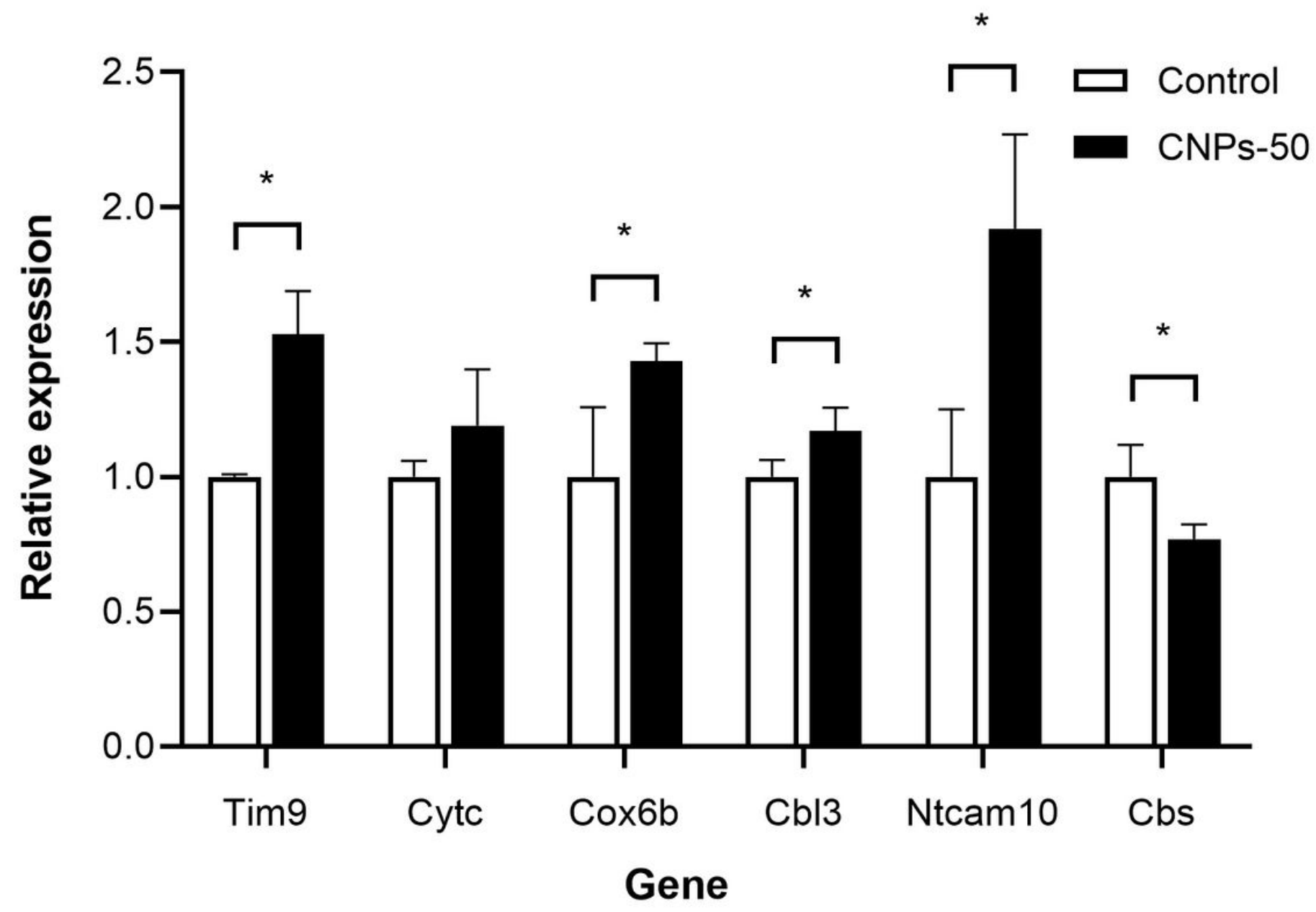

Figure 5

Confirmation of the differentially expressed proteins in response to CNPs by qRT-PCR analysis. Asterisks indicate significant differences between control and treatment determined by Student's t-test $(*, P<0.05$, $\star *, P<0.01)$. Error bars represent the standard error of three independent experiments. 


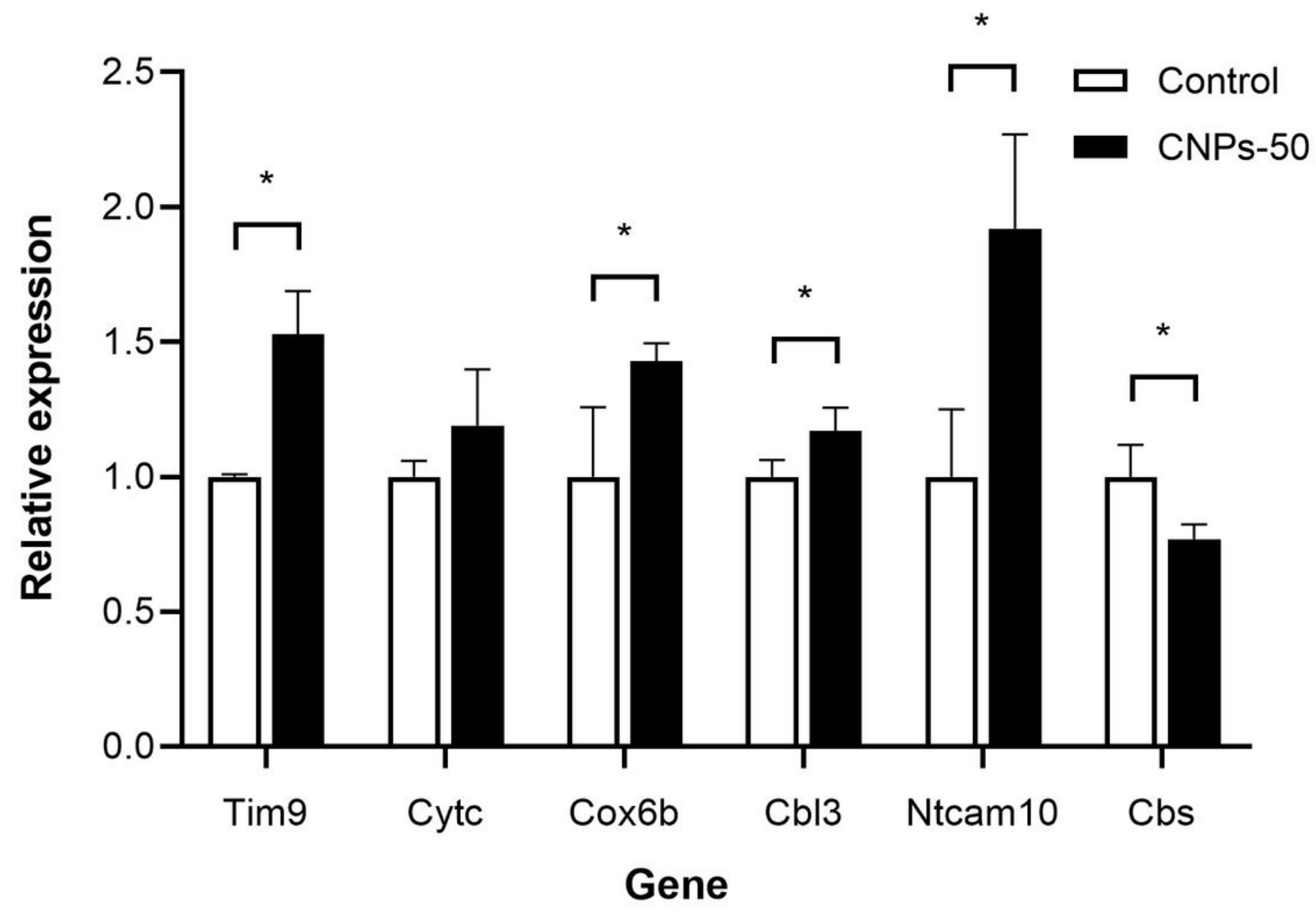

Figure 5

Confirmation of the differentially expressed proteins in response to CNPs by qRT-PCR analysis. Asterisks indicate significant differences between control and treatment determined by Student's t-test $(*, P<0.05$, $\star *, P<0.01)$. Error bars represent the standard error of three independent experiments.

\section{Supplementary Files}

This is a list of supplementary files associated with this preprint. Click to download.

- Supplementarytable1.xlsx

- Supplementarytable1.xlsx

- Supplementarytable2.xlsx

- Supplementarytable2.xlsx 